\begin{abstract}
Iranica
Abstracta Iranica Revue bibliographique pour le domaine irano-aryen

Volume 37-38-39 | 2018

Comptes rendus des publications de 2014-2016
\end{abstract}

\title{
Vladimir A. Livshits. Sogdian epigraphy of Central Asia and Semirech'e
}

Agnes Korn

\section{OpenEdition}

Édition électronique

URL : http://journals.openedition.org/abstractairanica/43001

DOI : 10.4000/abstractairanica.43001

ISBN : 1961-960X

ISSN : 1961-960X

Éditeur :

CNRS (UMR 7528 Mondes iraniens et indiens), Éditions de l'IFRI

Référence électronique

Agnes Korn, "Vladimir A. Livshits. Sogdian epigraphy of Central Asia and Semirech'e », Abstracta Iranica [En ligne], Volume 37-38-39 | 2018, document 7, mis en ligne le 30 décembre 2018, consulté le 10 décembre 2020. URL : http://journals.openedition.org/abstractairanica/43001 ; DOI : https://doi.org/ 10.4000/abstractairanica.43001

Ce document a été généré automatiquement le 10 décembre 2020.

Tous droits réservés 


\title{
Vladimir A. Livshits. Sogdian epigraphy of Central Asia and Semirech'e
}

\author{
Agnes Korn
}

\section{RÉFÉRENCE}

Vladimir A. Livshits. Sogdian epigraphy of Central Asia and Semirech'e. Translated by Tom Stableford, edited by Nicholas Sims-Williams. Londres, School of Oriental and African Studies, 2015, 315 p. (Corpus Inscriptionum Iranicarum, Part II, vol. III: Sogdian).

1 Le présent ouvrage est la traduction en anglais du livre Sogdijskaja èpigrafika Srednej Azii i Semirečjja (Saint-Petersbourg 2008; voir son compte-rendu dans le volume 31 d'Abstracta Iranica), préparée par Tom Stableford et éditée par les soins de Nicholas Sims-Williams. Il s'agit d'une collection d'ouvrages et d'articles sur l'épigraphie sogdienne publiés par l'A. depuis les années 1960 ainsi que l'édition de quelques inscriptions publiées pour la première fois dans la version russe du livre. Le volume est introduit par un résumé biographique préparé par I. M. Steblin-Kamenskii pour la version russe et se conclut par une bibliographie.

2 Au centre de l'ouvrage se trouve les Documents from Mount Mug: legal documents and letters (pp. 13-200) ; l'A. a entrepris des mises à jour importantes de son livre publié en 1962. On notera le très utile glossaire (p. 171-197) des mots contenus dans les documents trouvés sur ce site archéologique important qui comporte les ruines de la forteresse que les souverains sogdiens de Pendjikent avaient fait édifier à un point stratégique sur la rivière Zeravchan.

3 Puis, le volume contient neuf articles des années 1987-2006 (dont six furent d'abord publiés en russe). Là encore, l'A. n'a pas manqué d'apporter des modifications, de sorte que les articles publiés en anglais et traduits en russe pour l'édition de 2008 se présentent ici comme une nouvelle version par rapport à la publication originale. 
4 La troisième partie du livre, intitulée « Sogdian epigraphy of Semirech'e » (pp. 269-296), contient une discussion d'inscriptions provenant de sites très proches, des deux côtés de la frontière du Kazakhstan et du Kirghizstan. Un premier groupe comprend l'édition (description, lecture, commentaire, photos) de sept inscriptions sur des vases et d'une sur une pièce de schiste, et le deuxième groupe des inscriptions sur deux rochers (quatre au total).

5 La traduction anglaise suit l'original russe de façon assez étroite, permettant ainsi de retrouver aisément la formulation de ce dernier. Pour pouvoir comparer les deux éditions, la version anglaise mentionne également la numérotation des pages de l'édition de 2008. En outre, l'on a profité de l'occasion pour ajouter quelques photos qui manquaient dans la version russe (notons la très bonne photo d'un fragment bouddhique p. 256) et améliorer quelques autres (par ex. p. 296 : la photo de l'édition russe n'était pas la bonne inscription), mettre à jour la transcription du chinois, etc.

6 Le présent volume présente de façon très convenable et accessible en anglais une partie importante des travaux du feu auteur (1923-2017), iranologue éminent, sur les inscriptions sogdiennes et leurs interprétations philologique, linguistique et historique.

\section{AUTEURS}

\section{AGNES KORN}

CNRS, Mondes iranien et indien, Paris 